\title{
EFFECT OF CHEMICAL COMPOSITION ON MICROSTRUCTURE, HARDNESS AND ELECTRICAL CONDUCTIVITY PROFILES OF THE Bi-Cu-Ga ALLOYS AT $100^{\circ} \mathrm{C}$
}

\author{
Dejan Gurešićl ${ }^{1}$, Nadežda Talijan ${ }^{2}$, Vladan Ćosović ${ }^{2 *}$, Dušan Milisavljević ${ }^{1}$, \\ Aleksandar Đorđević ${ }^{1}$, Milica Tomovic ${ }^{1}$ \\ ${ }^{1}$ University in Priština, Faculty of Technical Science, K.M. 7, \\ 4000 Kos. Mitrovica, Serbia \\ ${ }^{2}$ University of Belgrade, Institute of Chemistry, Technology and Metallurgy, \\ Belgrade, Serbia
}

Received 14.07.2016

Accepted 06.09.2016

\begin{abstract}
Theoretical calculation and experimental investigation of the isothermal section of a ternary $\mathrm{Bi}-\mathrm{Cu}-\mathrm{Ga}$ system at $100{ }^{\circ} \mathrm{C}$ are presented in this paper. Thermodynamic binary-based calculation of the isothermal section was performed using Pandat software. Experimental investigation included microstructural analysis carried out using light optical microscopy (LOM) and scanning electron microscopy with energy dispersive spectroscopy (SEM-EDS), phase composition analysis using X-ray diffraction (XRD), Brinell and Vickers hardness testing and electrical conductivity measurements. In total, thirty alloy samples with compositions along three vertical sections $\mathrm{Bi}-\mathrm{CuGa}, \mathrm{Cu}-\mathrm{BiGa}$ and $\mathrm{Ga}-\mathrm{BiCu}$ were studied. The obtained experimental results support the calculated phase regions of the isothermal section at $100{ }^{\circ} \mathrm{C}$. Hardness of individual phases as well as hardness and electrical conductivity of the studied alloys were measured. Based on the experimentally obtained results iso-lines of Brinell hardness and electrical conductivity along the whole compositional range were calculated by using appropriate mathematical models.

Keywords: ternary Bi-Cu-Ga system, isothermal section at $100{ }^{\circ} \mathrm{C}$, microstructural investigation, hardness test, electrical conductivity

\section{Introduction}

It is well known that $\mathrm{Cu}$ and $\mathrm{Cu}$ based alloys are very important for electronic industry. In addition to good electrical and thermal conductivity and corrosion
\end{abstract}

\footnotetext{
*Corresponding author: Vladan Ćosović, vlada@tmf.bg.ac.rs
} 
resistance [1-7] it is significant that all used copper is recyclable without any loss of quality. Also copper can easily make alloys with a variety of elements [8-10]. The most important copper alloys are brass [11] and bronze [12] while the largest percentage of copper is used for production of wires for power transfer.

To the best of our knowledge there are no studies on ternary $\mathrm{Bi}-\mathrm{Cu}-\mathrm{Ga}$ system in literature. Hence, the selection of temperature for the isothermal section i.e. for the study of alloy samples was based on analysis of the predicted phase diagrams of three binary subsystems $\mathrm{Bi}-\mathrm{Ga}$ [13], $\mathrm{Bi}-\mathrm{Cu}[14]$ and $\mathrm{Cu}-\mathrm{Ga}$ [15], that are presented on Fig. 1. From the calculated Bi-Ga phase diagram presented on Fig. 1a it can be seen that in temperature range $\approx 30$ to $\approx 222{ }^{\circ} \mathrm{C} \mathrm{L}+(\mathrm{Bi})$ phase is stable. The second binary subsystem $\mathrm{Bi}-\mathrm{Cu}$ [14] (Fig. 1b) is eutectic system with eutectic reaction at $270.5{ }^{\circ} \mathrm{C}$ while the $(\mathrm{Bi})+(\mathrm{Cu})$ phase region is stable from 0 up to eutectic temperature. The third binary system $\mathrm{Cu}-\mathrm{Ga}$ [15] presented at Fig. 1c is more complex than the other two and along all compositional ranges in temperature interval $\approx 30$ to $\approx 260{ }^{\circ} \mathrm{C}$ the same phase regions are present. Although, the ternary $\mathrm{Bi}-\mathrm{Cu}-\mathrm{Ga}$ system itself has not been thoroughly investigated the three binary subsystems $\mathrm{Bi}-\mathrm{Ga}$ [16-18], $\mathrm{Bi}-\mathrm{Cu}$ [19-21] and $\mathrm{Cu}-\mathrm{Ga}$ [22$24]$ have been investigated over the years by a number of different research groups.
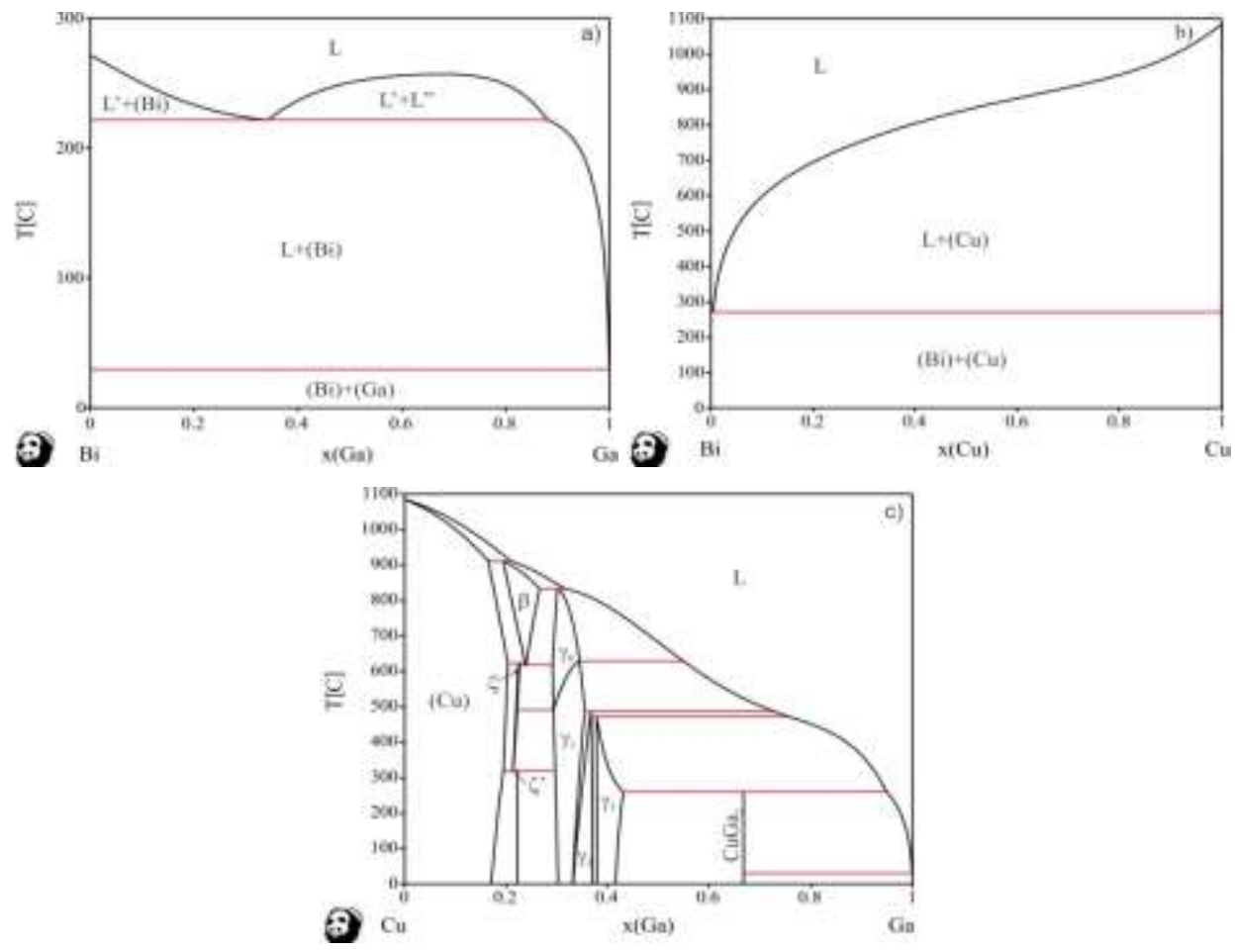

Fig. 1. Calculated phase diagrams of the binary subsystems: a) Bi-Ga [13], b) Bi-Cu [14] and c) Cu-Ga [15] 
Taking into account that the working temperature of $\mathrm{Cu}$ wires is from 70 to $90{ }^{\circ} \mathrm{C}$, the isothermal section at $100{ }^{\circ} \mathrm{C}$ was selected for investigation. The prepared alloys from the selected isothermal section were characterized in terms of microstructure, chemical and phase composition, Brinell and Vickers hardness and electrical conductivity.

\section{Experimental}

The studied alloy samples were prepared from high purity elements $\mathrm{Bi}, \mathrm{Cu}$ and $\mathrm{Ga}$ (99.999 at. \%). Weight of the alloy samples was $3 \mathrm{~g}$. The samples were melted in an induction furnace under inert atmosphere (Ar) and the average loss of mass during melting was about 1.5 at. \%. Subsequently, all samples were placed in evacuated quartz tubes and sealed, then annealed at $100{ }^{\circ} \mathrm{C}$ for 2 months and at the end quenched into an ice/water mixture in order to preserve the equilibriums. Microstructure of the samples was observed by inverted light optical microscopy (LOM) using OLYMPUS GX41 metallographic microscope. Additional microstructural analysis was carried out on JEOL (JSM6460) scanning electron microscope with energy dispersive spectroscopy (EDS) (Oxford Instruments X-act). Homogeneity and composition off the prepared alloy samples were checked by EDS elemental mapping. Overall composition and compositions of coexisting phases was determined using EDS. X-ray diffraction analysis (XRD) was performed on D2 PHASER powder diffractometer equipped with a dynamic scintillation detector and ceramic X-ray $\mathrm{Cu}$ tube $(\mathrm{KFLCu}-2 \mathrm{~K})$ in a $2 \theta$ range of 5 to $75 \mathrm{deg}$ with a step size of $0.02 \mathrm{deg}$. The patterns were analyzed using Topas 4.2 software and ICDD databases PDF2 (2013). Electrical conductivity measurements were carried out using Foerster SIGMATEST 2.069 eddy current instrument. Hardness of the samples was determined using Brinell hardness tester INNOVATEST Nexus 3001 by applying force of $294.2 \mathrm{~N}$ and time of loading 20 seconds. Hardness of the observed phases was determined using Digital micro Vickers hardness tester DHV-1000, applied force was $0.245 \mathrm{~N}$ and time of loading 20 seconds. All investigated alloy samples except for those investigated by XRD were prepared by a classic metallographic procedure without etching.

Thermodynamic data from literature were used for calculation of isothermal section of Bi-Cu-Ga ternary system at $100{ }^{\circ} \mathrm{C}$. Data for the $\mathrm{Bi}-\mathrm{Ga}$ system were taken from Girard [13], for the Bi-Cu system from Teppo et al. [14], and for the $\mathrm{Cu}-\mathrm{Ga}$ system from Li et al. [15]. Gibbs energy functions for the unary phases were taken from the SGTE compilation by Dinsdale [25]. Calculations were carried out using PANDAT software [26]. The phases from the constitutive binary subsystems considered for thermodynamic binary-based prediction together with their corresponding Pearson symbols are given in Table 1 . 
Table 1. Considered phases and their crystal structures

\begin{tabular}{|c|c|c|c|}
\hline $\begin{array}{l}\text { Thermodynamic } \\
\text { database name }\end{array}$ & Phase & $\begin{array}{l}\text { Pearson } \\
\text { symbol }\end{array}$ & Space \\
\hline LIQUID & $\mathrm{L}$ & - & - \\
\hline FCC_A1 & $(\mathrm{Cu})$ & $\mathrm{cF} 4$ & Fm3m \\
\hline RHOMBO_A7 & (Bi) & $h R 2$ & $R \overline{3} m$ \\
\hline ORTHOMBIC & $(\mathrm{Ga})$ & $o C 8$ & Cmca \\
\hline BCC_A2 & $\beta$ & $\mathrm{cI} 2$ & $\operatorname{Im} 3 \mathrm{~m}$ \\
\hline HCP_A3 & $\zeta$ & $\mathrm{hP2}$ & $\mathrm{P}_{3} / \mathrm{mmc}$ \\
\hline CU8GA2_ZETA & $\zeta$ & $\ldots$ & $\ldots$ \\
\hline CU9GA4_GAMMA0 & $\gamma_{0}$ & oP52 & $\mathrm{P} \overline{4} 3 \mathrm{~m}$ \\
\hline CU9GA4_GAMMA1 & $\gamma_{1}$ & oP52 & $\mathrm{P} \overline{4} 3 \mathrm{~m}$ \\
\hline CU9GA4_GAMMA2 & $\gamma_{2}$ & $\mathrm{cP} ?$ & $\mathrm{P} 43 \mathrm{~m}$ \\
\hline CU9GA4_GAMMA3 & $\gamma_{3}$ & $\mathrm{cP}$ ? & $\mathrm{P} \overline{4} 3 \mathrm{~m}$ \\
\hline CUGA2 & $\mathrm{CuGa}_{2}$ & tP3 & $\mathrm{P} 4 / \mathrm{mmm}$ \\
\hline
\end{tabular}

\section{Results and discussion}

Thirty alloy samples from the isothermal section at $100{ }^{\circ} \mathrm{C}$ were prepared for investigation, from which 27 are ternary alloys and three are binary alloys. Compositions of the all thirty samples lay along three vertical sections (Bi-CuGa, $\mathrm{Cu}-\mathrm{BiGa}$ nad $\mathrm{Ga}-\mathrm{CuBi}$ ), that originate from all three corners of pure elements while the another two elements were added in the same ratio. Calculated isothermal section at $100{ }^{\circ} \mathrm{C}$ is presented on Fig. 2 together with experimentally determined compositions (EDS elemental mapping) of the investigated samples.

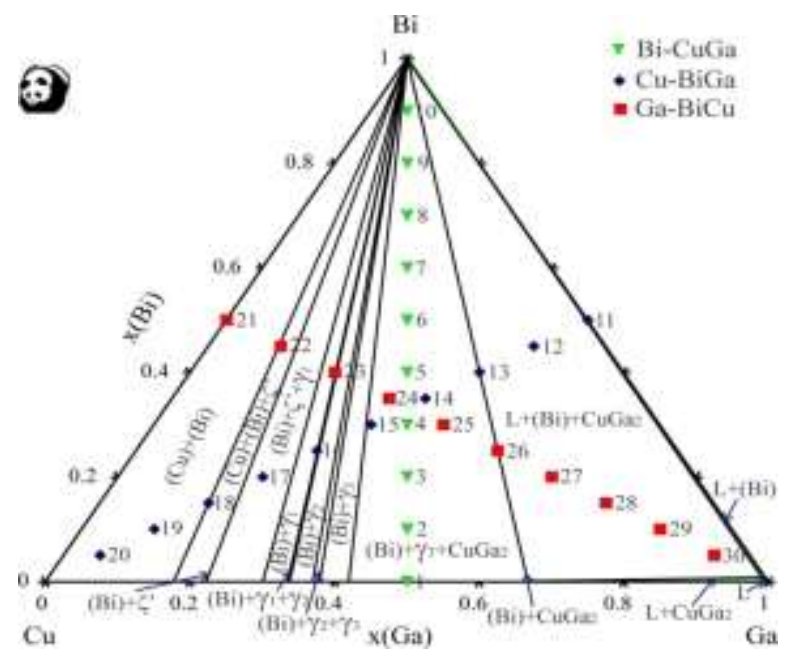

Fig. 2. Isothermal section of the ternary Bi-Cu-Ga system at $100^{\circ} \mathrm{C}$ with marked overall compositions of the investigated samples 
As can be seen from Fig. 2, the calculated isothermal section at $100{ }^{\circ} \mathrm{C}$ consists of fifteen different regions. The investigated alloy samples belong to seven different regions. Majority of the samples are from two largest three-phase regions $\mathrm{L}+(\mathrm{Bi})+\mathrm{CuGa}_{2}$ and $(\mathrm{Bi})+\mathrm{CuGa}_{2}+\gamma_{3}$ while the rest are from three three-phase regions $(\mathrm{Bi})+\gamma_{1}+\gamma_{2},(\mathrm{Bi})+\gamma_{1}+\zeta^{\prime}$ and $(\mathrm{Bi})+(\mathrm{Cu})+\zeta$ ' and two two-phase regions $(\mathrm{Bi})+(\mathrm{Cu})$ and (Bi) $+\mathrm{CuGa}_{2}$. The obtained results of the combined SEM-EDS analysis of the nine alloy samples are presented in Table 2, together with theoretically predicted phase compositions.

Table 2. Calculated and experimentally determined phase compositions of the studied alloys

\begin{tabular}{|c|c|c|c|c|c|c|c|c|c|}
\hline \multirow{3}{*}{ Sample } & \multirow{3}{*}{$\begin{array}{c}\text { Overall } \\
\text { composition } \\
\text { (at. } \%)\end{array}$} & \multirow{3}{*}{$\begin{array}{l}\text { Theoretic. } \\
\text { Predicted } \\
\text { phases }\end{array}$} & \multirow{3}{*}{$\begin{array}{c}\text { Experiment. } \\
\text { Determined } \\
\text { phases }\end{array}$} & \multicolumn{6}{|c|}{ Compositions of phases (at.\%) } \\
\hline & & & & \multicolumn{2}{|l|}{$\mathrm{Bi}$} & \multicolumn{2}{|l|}{$\mathrm{Cu}$} & \multicolumn{2}{|l|}{$\mathrm{Ga}$} \\
\hline & & & & exp. & calc. & exp. & calc. & exp. & calc. \\
\hline \multirow{3}{*}{2} & & (Bi) & (Bi) & $98.17 \pm 0.1$ & 100.00 & $0.80 \pm 0.3$ & - & $1.03 \pm 0.1$ & - \\
\hline & 45.17 & $\gamma_{3}$ & $\gamma_{3}$ & $0.17 \pm 0.3$ & - & $57.01 \pm 0.3$ & 58.10 & $42.82 \pm 0.4$ & 41.90 \\
\hline & $44.80 \mathrm{Ga}$ & $\mathrm{CuGa}_{2}$ & $\mathrm{CuGa}_{2}$ & $0.34 \pm 0.2$ & - & $32.19 \pm 0.2$ & 33.33 & $67.47 \pm 0.1$ & 66.67 \\
\hline \multirow{3}{*}{6} & $51.03 \mathrm{Bi}$ & $(\mathrm{Bi})$ & $(\mathrm{Bi})$ & $99.07 \pm 0.1$ & 100.00 & $0.45 \pm 0.6$ & - & $0.48 \pm 0.1$ & - \\
\hline & $25.03 \mathrm{Cu}$ & $\gamma_{3}$ & $\gamma_{3}$ & $0.08 \pm 0.1$ & - & $57.01 \pm 0.2$ & 58.10 & $42.91 \pm 0.3$ & 41.90 \\
\hline & 23.94 & $\mathrm{CuGa}_{2}$ & $\mathrm{CuGa}_{2}$ & $0.28 \pm 0.4$ & - & $32.01 \pm 0.2$ & 33.33 & $67.71 \pm 0.2$ & 66.67 \\
\hline \multirow{3}{*}{8} & & (Bi) & $(\mathrm{Bi})$ & $98.54 \pm 0.7$ & 100.00 & $0.87 \pm 0.4$ & - & $0.59 \pm 0.3$ & - \\
\hline & $\mathrm{Cu}$ & $\gamma_{3}$ & $\gamma_{3}$ & $0.54 \pm 0.2$ & - & $57.29 \pm 0.2$ & 58.10 & $42.17 \pm 0.6$ & 41.90 \\
\hline & 14.5 & $\mathrm{CuGa}_{2}$ & $\mathrm{CuGa}_{2}$ & $0.23 \pm 0.5$ & - & $33.89 \pm 0.2$ & 33.33 & $65.88 \pm 0.2$ & 66.67 \\
\hline \multirow{3}{*}{10} & $90.89 \mathrm{Bi}$ & $(\mathrm{Bi})$ & $(\mathrm{Bi})$ & $99.70 \pm 0.4$ & 100.00 & $0.25 \pm 0.3$ & - & $0.05 \pm 0.4$ & - \\
\hline & $4.43 \mathrm{Cu}$ & $\gamma_{3}$ & $\gamma_{3}$ & $0.14 \pm 0.1$ & - & $59.78 \pm 0.3$ & 58.10 & $40.08 \pm 0.3$ & 41.90 \\
\hline & $4.68 \mathrm{Ga}$ & $\mathrm{CuGa}_{2}$ & $\mathrm{CuGa}_{2}$ & $0.11 \pm 0.6$ & - & $34.25 \pm 0.5$ & 33.33 & $65.64 \pm 0.3$ & 66.67 \\
\hline \multirow{3}{*}{17} & $19.45 \mathrm{Bi}$ & $(\mathrm{Bi})$ & $(\mathrm{Bi})$ & $98.20 \pm 0.1$ & 100 & $0.78 \pm 0.2$ & - & $1.02 \pm 0.6$ & - \\
\hline & $60.87 \mathrm{Cu}$ & $\gamma_{1}$ & $\gamma_{1}$ & $0.09 \pm 0.1$ & - & $70.76 \pm 0.5$ & 69.98 & $29.15 \pm 0.1$ & 30.02 \\
\hline & $19.68 \mathrm{Ga}$ & $\zeta$ & $\zeta$ & $0.15 \pm 0.5$ & - & $76.34 \pm 0.5$ & 77.80 & $23.51 \pm 0.2$ & 22.20 \\
\hline \multirow{3}{*}{18} & $15.54 \mathrm{Bi}$ & (Bi) & (Bi) & $99.12 \pm 0.3$ & 100 & $0.67 \pm 0.1$ & - & $0.21 \pm 0.5$ & - \\
\hline & $9.84 \mathrm{Cu}$ & $(\mathrm{Cu})$ & $(\mathrm{Cu})$ & $0.43 \pm 0.3$ & - & $81.75 \pm 0.3$ & 82.34 & $17.82 \pm 0.3$ & 17.66 \\
\hline & 14.6 & $\zeta$ & $\zeta$ & $0.33 \pm 0.2$ & - & $78.55 \pm 0.2$ & 77.80 & $21.12 \pm 0.3$ & 22.20 \\
\hline \multirow[b]{2}{*}{19} & $9.98 \mathrm{Bi}$ & & & & & & & & - \\
\hline & $\begin{array}{c}80.10 \mathrm{Cu} \\
9.92 \mathrm{Ga}\end{array}$ & (Cu) & (Cu) & $0.33 \pm 0.1$ & - & $81.82 \pm 0.3$ & 82.34 & $17.85 \pm 0.2$ & 17.66 \\
\hline \multirow{3}{*}{22} & $44.98 \mathrm{Bi}$ & (Bi) & (Bi) & $98.93 \pm 0.1$ & 100 & $0.25 \pm 0.5$ & - & $0.82 \pm 0.5$ & - \\
\hline & $45.15 \mathrm{Cu}$ & $(\mathrm{Cu})$ & $(\mathrm{Cu})$ & $0.27 \pm 0.5$ & - & $82.66 \pm 0.3$ & 82.34 & $17.07 \pm 0.3$ & 17.66 \\
\hline & $9.87 \mathrm{Ga}$ & $\zeta$ & $\zeta$ & $0.47 \pm 0.3$ & - & $77.34 \pm 0.3$ & 77.80 & $22.19 \pm 0.3$ & 22.20 \\
\hline \multirow{3}{*}{28} & $15.67 \mathrm{Bi}$ & $\mathrm{L}$ & $\mathrm{L}$ & $0.13 \pm 0.1$ & 0.76 & $0.63 \pm 0.4$ & 0.57 & $99.24 \pm 0.5$ & 98.67 \\
\hline & $13.56 \mathrm{Cu}$ & (Bi) & (Bi) & $98.93 \pm 0.8$ & 100.00 & $0.34 \pm 0.5$ & - & $0.73 \pm 0.6$ & - \\
\hline & $70.77 \mathrm{Ga}$ & $\mathrm{CuGa}_{2}$ & $\mathrm{CuGa}_{2}$ & $0.45 \pm 0.2$ & - & $32.17 \pm 0.1$ & 33.33 & $67.38 \pm 0.1$ & 66.67 \\
\hline
\end{tabular}

According to the carried out thermodynamic calculations the samples 2, 6, 8 and 10 belong to three-phase region $(\mathrm{Bi})+\mathrm{CuGa}_{2}+\gamma_{3}$. The obtained results of EDS analysis confirm existence of these three phases in the samples 2, 6, 8 and 10. Moreover, the results show that solubility of $\mathrm{Ga}$ and $\mathrm{Cu}$ in solid solution (Bi) are around 1 at. \%. The other two phases $\mathrm{CuGa}_{2}$ and $\gamma_{3}$ can dissolve $\mathrm{Bi}$ in small amounts, maximum up to 0.54 at. $\%$. The experimental results show presence of three phases $(\mathrm{Bi})+\gamma_{1}+\zeta$ ' in the sample 17 , which is in agreement with the thermodynamic predictions. The samples 18 and 22 
belong to three phase region $(\mathrm{Bi})+(\mathrm{Cu})+\zeta$ ' which is also confirmed by EDS whereas the sample 19 belongs to two phase region $(\mathrm{Bi})+(\mathrm{Cu})$. The detected solid solution $(\mathrm{Bi})$ dissolves only small amount of $\mathrm{Cu}$ and $\mathrm{Ga}$ which is negligible while solid solution $(\mathrm{Cu})$ can dissolve 17.66 at. \% of $\mathrm{Ga}$ which is allowed by thermodynamic calculations. Also, three phases, $\mathrm{L},(\mathrm{Bi})$ and $\mathrm{CuGa}_{2}$ were identified in the microstructure of the sample 28 . Some of the analyzed microstructures are illustrated by the obtained SEM images presented on Fig. 3. The detected phases are marked with the corresponding symbols of the individual phases given in Table 1 .

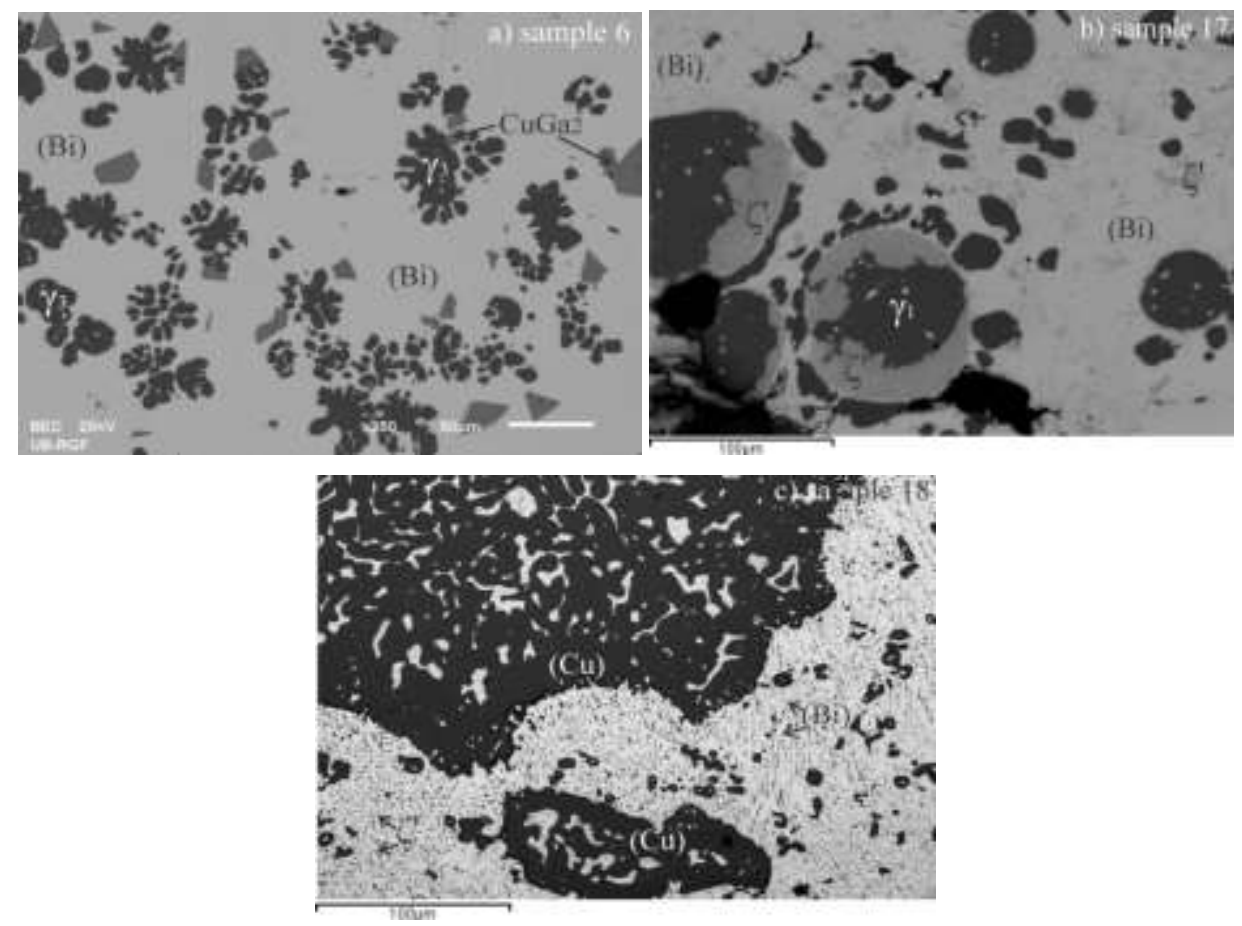

Fig. 3. Selected microstructures of the alloys analyzed by the SEM-EDS technique

In order to additionally confirm phase compositions of the studied alloy samples determined by SEM-EDS technique and predicted by thermodynamic calculations ten samples were selected for further investigation by XRD. The obtained results of XRD analysis are presented in Table 3.

Generally speaking, the obtained results of XRD analysis support the results of SEM-EDS and the theoretical predictions. For the ten alloy samples 3, 5, 7, 9, 14, 15, 25, 26, 27 and 29 the same phase composition was determined both by XRD and SEMEDS analysis. In addition to confirmation of phase composition, lattice parameters for the detected phases were calculated and compered with literature data. In total, three different phases $(\mathrm{Bi}), \gamma_{3}$ and $\mathrm{CuGa}_{2}$ were identified in the ten studied alloy samples. Lattice parameters from literature [27-29] are presented in Table 3 next to the calculated ones. Similarity between calculated and literature values is clearly visible. 
Table 3. Results of XRD analysis: identified phases and calculated lattice parameters compared with literature data

\begin{tabular}{|c|c|c|c|c|c|c|c|}
\hline \multirow{3}{*}{ S. } & \multirow{3}{*}{$\begin{array}{c}\text { Overall } \\
\text { composition } \\
\text { (at.\%) }\end{array}$} & \multicolumn{2}{|c|}{ Coexisting phases } & \multicolumn{4}{|c|}{ Lattice parameters $(\AA)$} \\
\hline & & \multirow{2}{*}{$\begin{array}{c}\text { SEM- } \\
\text { EDS }\end{array}$} & \multirow{2}{*}{ XRD } & \multicolumn{2}{|c|}{$a=b$} & \multicolumn{2}{|r|}{$\mathrm{c}$} \\
\hline & & & & Exp. & Ref. & Exp. & Ref. \\
\hline \multirow{3}{*}{3} & $20.19 \mathrm{Bi}$ & $(\mathrm{Bi})$ & (Bi) & $4.5487(1)$ & $4.548(5)[27]$ & 11.8589(2) & $11.852(12)[27]$ \\
\hline & $39.75 \mathrm{Cu}$ & $\gamma_{3}$ & $\gamma_{3}$ & $8.7456(5)$ & $8.747(2)[28]$ & & \\
\hline & $40.06 \mathrm{Ga}$ & $\mathrm{CuGa}_{2}$ & $\mathrm{CuGa}_{2}$ & $2.8365(3)$ & $2.830[29]$ & $5.8378(1)$ & $5.839[29]$ \\
\hline \multirow{3}{*}{5} & $40.17 \mathrm{Bi}$ & $(\mathrm{Bi})$ & $(\mathrm{Bi})$ & $4.5478(3)$ & $4.548(5)[27]$ & 11.8527(6) & $11.852(12)[27]$ \\
\hline & $29.8^{7}$ & $\gamma_{3}$ & $\gamma_{3}$ & $8.7456(2)$ & $8.747(2)[28]$ & & \\
\hline & $29.96 \mathrm{Ga}$ & $\mathrm{CuGa}_{2}$ & $\mathrm{CuGa}_{2}$ & $2.8309(2)$ & $2.830[29]$ & $5.8309(2)$ & $5.839[29]$ \\
\hline \multirow{3}{*}{7} & 59.7 & $(\mathrm{Bi})$ & $(\mathrm{Bi})$ & $4.5425(1)$ & $4.548(5)[27]$ & 11.8534(1) & $11.852(12)[27]$ \\
\hline & 20.8 & $\gamma_{3}$ & $\gamma_{3}$ & $8.7498(1)$ & $8.747(2)[28]$ & & \\
\hline & 19.38 & $\mathrm{CuGa}_{2}$ & $\mathrm{CuGa}_{2}$ & $2.8345(3)$ & $2.830[29]$ & $5.8368(1)$ & $5.839[29]$ \\
\hline \multirow{3}{*}{9} & 80.58 & (Bi) & (Bi) & $4.5493(2)$ & $4.548(5)[27]$ & $11.8536(3)$ & $11.852(12)[27]$ \\
\hline & 9.92 & $\gamma_{3}$ & $\gamma_{3}$ & $8.7467(5)$ & $8.747(2)[28]$ & & \\
\hline & $9.50 \mathrm{Ga}$ & $\mathrm{CuGa}_{2}$ & $\mathrm{CuGa}_{2}$ & $2.8347(6)$ & 2.830 [29] & $5.8306(4)$ & 5.839 [29] \\
\hline \multirow{3}{*}{14} & $35.03 \mathrm{Bi}$ & $(\mathrm{Bi})$ & $(\mathrm{Bi})$ & $4.5467(7)$ & $4.548(5)[27]$ & 11.8578(2) & $11.852(12)[27]$ \\
\hline & $30.15 \mathrm{Cu}$ & $\gamma_{3}$ & $\gamma_{3}$ & $8.7496(6)$ & $8.747(2)[28]$ & & \\
\hline & $34.82 \mathrm{Ga}$ & $\mathrm{CuGa}_{2}$ & $\mathrm{CuGa}_{2}$ & $2.8320(5)$ & $2.830[29]$ & $5.8387(9)$ & 5.839 [29] \\
\hline \multirow{3}{*}{15} & $30.19 \mathrm{Bi}$ & (Bi) & (Bi) & $4.5498(1)$ & $4.548(5)[27]$ & $11.8567(5)$ & $11.852(12)[27]$ \\
\hline & $39.78 \mathrm{Cu}$ & $\gamma_{3}$ & $\gamma_{3}$ & $8.7498(9)$ & $8.747(2)[28]$ & & \\
\hline & $30.03 \mathrm{Ga}$ & $\mathrm{CuGa}_{2}$ & $\mathrm{CuGa}_{2}$ & $2.8376(6)$ & $2.830[29]$ & $5.8327(3)$ & $5.839[29]$ \\
\hline \multirow{3}{*}{25} & $30.17 \mathrm{Bi}$ & (Bi) & (Bi) & $4.5479(1)$ & $4.548(5)[27]$ & 11.8576(3) & $11.852(12)[27]$ \\
\hline & 30.0 & $\gamma_{3}$ & $\gamma_{3}$ & $8.7453(3)$ & $8.747(2)[28]$ & & \\
\hline & $39.81 \mathrm{Ga}$ & $\mathrm{CuGa}_{2}$ & $\mathrm{CuGa}_{2}$ & $2.8390(2)$ & 2.830 [29] & $5.8365(5)$ & $5.839[29]$ \\
\hline \multirow[b]{2}{*}{26} & $24.87 \mathrm{Bi}$ & (Bi) & (Bi) & $4.5492(3)$ & $4.548(5)$ & $11.8587(9)$ & $11.852(12)[27]$ \\
\hline & $\begin{array}{l}25.39 \mathrm{Cu} \\
49.74 \mathrm{Ga}\end{array}$ & $\mathrm{CuGa}_{2}$ & $\mathrm{CuGa}_{2}$ & $2.8356(1)$ & $2.830[29]$ & $5.8345(1)$ & $5.839[29]$ \\
\hline \multirow{3}{*}{27} & $19.76 \mathrm{Bi}$ & $\mathrm{L}$ & - & & & & $\cos ^{-}$ \\
\hline & $20.05 \mathrm{Cu}$ & (Bi) & (Bi) & $4.5487(9)$ & $4.548(5)[27]$ & 11.8512(3) & $11.852(12)[27]$ \\
\hline & $60.19 \mathrm{Ga}$ & $\mathrm{CuGa}_{2}$ & $\mathrm{CuGa}_{2}$ & $2.8339(1)$ & $2.830[29]$ & $5.8354(4)$ & $5.839[29]$ \\
\hline \multirow{3}{*}{29} & $9.78 \mathrm{Bi}$ & & . & & & & \\
\hline & $9.69 \mathrm{Cu}$ & (Bi) & (Bi) & $4.5476(6)$ & $4.548(5)[27]$ & $11.8554(9)$ & $11.852(12)[27]$ \\
\hline & $80.53 \mathrm{Ga}$ & $\mathrm{CuGa}_{2}$ & $\mathrm{CuGa}_{2}$ & $2.8358(5)$ & 2.830 [29] & $5.8367(1)$ & 5.839 [29] \\
\hline
\end{tabular}

The prepared alloy samples were further investigated by Vickers micro-hardness test. Determined values of hardness for the individual phases are given in Table 4. The presented values represent an average for individual phase hardness measured in all studied samples in which the particular phase is present. For example, intermetallic compound $\mathrm{CuGa}_{2}$ is detected within sixteen alloy samples. For one sample, hardness of the individual phases was measured approximately five times at different parts of the sample. This means that the reported value for hardness of $\mathrm{CuGa}_{2}$ phase in Table 4 represents average of eighty measurements. The same procedure was applied for each phase. 
Table 4. Vickers microhardness of the detected phases in the ternary Bi-Cu-Ga system

\begin{tabular}{|c|c|c|c|c|c|c|c|}
\hline \multirow{2}{*}{ micro-Vickers } & \multicolumn{7}{|c|}{ Detected phase with EDS and XRD } \\
\cline { 2 - 8 } & $(\mathrm{Cu})$ & $(\mathrm{Bi})$ & $\zeta^{\prime}$ & $\gamma_{1}$ & $\gamma_{2}$ & $\gamma_{3}$ & $\mathrm{CuGa}_{2}$ \\
\hline $\begin{array}{c}\text { Mean value } \\
\mathrm{MN} / \mathrm{m}^{2}\end{array}$ & 908.13 & 80.17 & 308.91 & 245.35 & 222.61 & 214.89 & 157.46 \\
\hline
\end{tabular}

LOM images of microstructures of the samples 9 and 19 after micro-Vickers measurements are presented on Fig. 4.
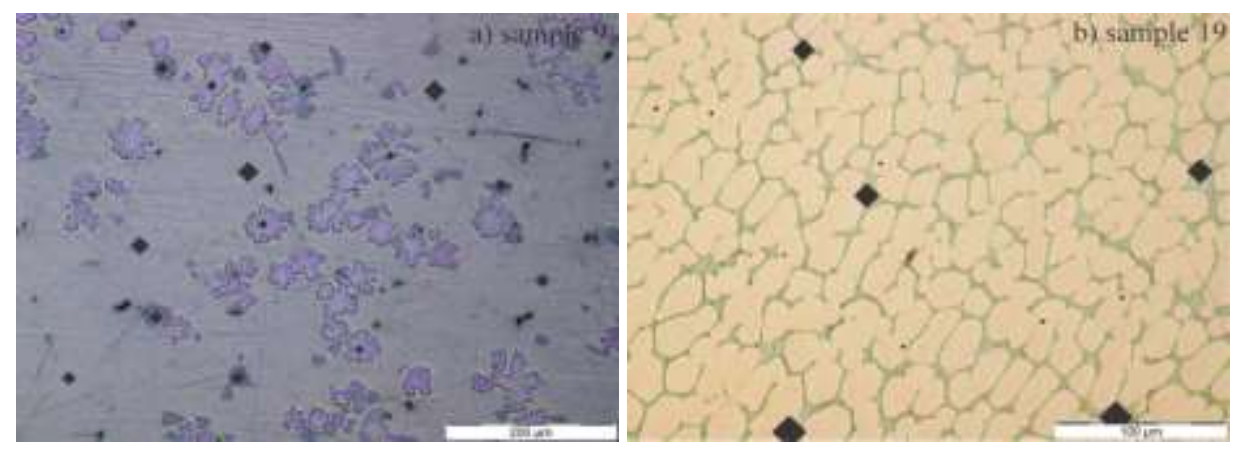

Fig. 4. Microstructures of the alloys after micro-Vickers test: a) sample 9 and b) sample 19

Brinell hardness tests were performed on all prepared alloy samples from the studied ternary system as well as on three binary alloys. The obtained average values after three measurements are presented on Fig. 5 in relation to alloy composition. Considering values of Brinell hardness for the pure elements $\mathrm{Bi}\left(94.2 \mathrm{MN} / \mathrm{m}^{2}\right), \mathrm{Cu}$ $\left(874 \mathrm{MN} / \mathrm{m}^{2}\right)$ and $\mathrm{Ga}\left(60 \mathrm{MN} / \mathrm{m}^{2}\right)$ [30] the observed increase of alloy hardness with an increase of copper content (Fig. 5b) is expected. Similarly, the $\mathrm{Cu}$ rich alloy (sample 20) has the highest hardness $492.47 \mathrm{MN} / \mathrm{m}^{2}$.
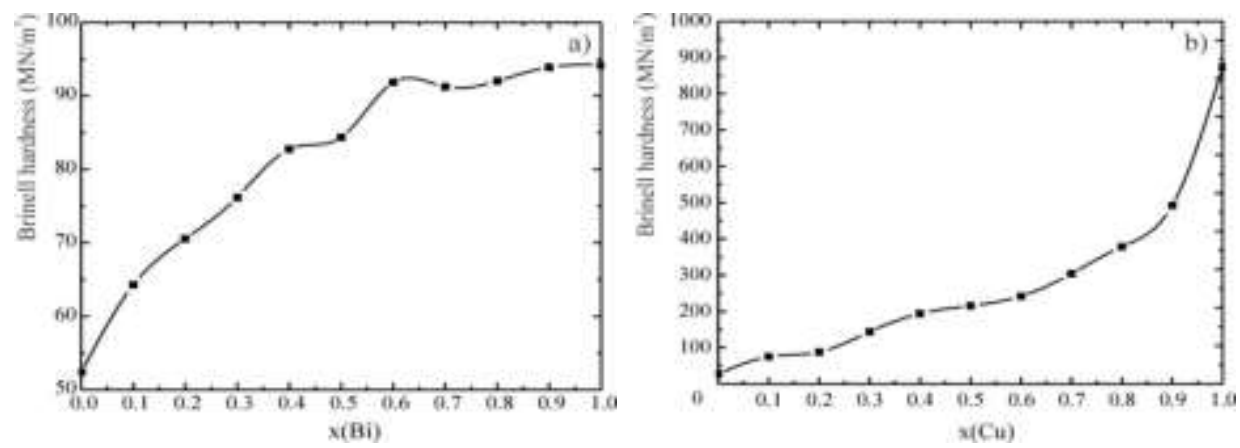


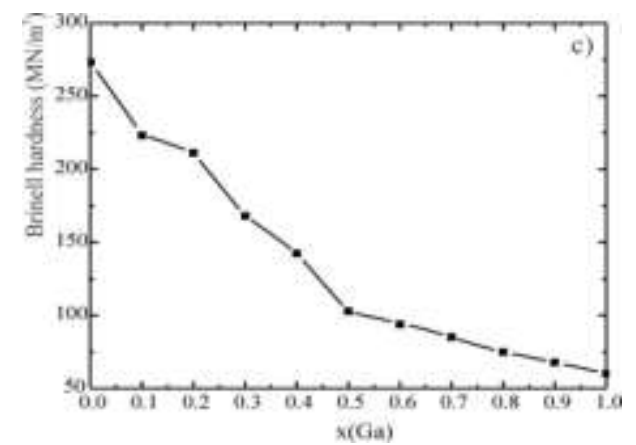

Fig. 5. Graphical presentation of the measured Brinell hardness of the investigated samples: a) $\mathrm{Bi}-\mathrm{Cu} \mathrm{Ga}$, b) $\mathrm{Cu}-\mathrm{BiGa}$ and c) $\mathrm{Ga}-\mathrm{BiCu}$

From Fig. 5 it can be seen that the hardness of $\mathrm{CuGa}$ alloys increases with addition of $\mathrm{Bi}$. Likewise, $\mathrm{BiGa}$ alloys behave in the similar manner as an increase of hardness can be observed with the addition of $\mathrm{Cu}$. However, in this case, the increase of hardness is much more significant. In contrast, the alloys from $\mathrm{Ga}-\mathrm{BiCu}$ vertical section exhibit quite opposite behavior as the hardness of the alloys $\mathrm{BiCu}$ decreases with addition of $\mathrm{Ga}$.

By using experimental results and appropriate mathematical model it is possible to obtain values of hardness along the entire compositional range. To define a mathematical model of dependence of Brinell hardness vs composition of the studied alloys the software package Desig Expert v.9.0.3.1 was used. Out of a possible canonical or Scheffe models [31-33] that meet the requirements of adequacy, the Special Quartic Mixture Model is recommended. Adequacy of the model was confirmed by the Analysis of variance (ANOVA) and the final equation of the predictive model in terms of actual components is:

$$
H B\left(M N / m^{2}\right)=9.36810 \cdot x(B i)+27.39840 \cdot x(C u)+9.57134 \cdot x(G a)-
$$

$3.47309 \cdot x(B i) \cdot x(C u)-15.23695 \cdot x(B i) \cdot x(G a)-46.61845 \cdot x(C u) \cdot x(G a)+252.66687 \cdot x(B i)$

$\cdot x(C u) \cdot x(G a)^{2}$

Iso-lines contour plot of Brinell hardness of the alloys from the $\mathrm{Bi}-\mathrm{Cu}-\mathrm{Ga}$ ternary system at $100^{\circ} \mathrm{C}$ defined by equation 1 is shown on Fig. 6 . 


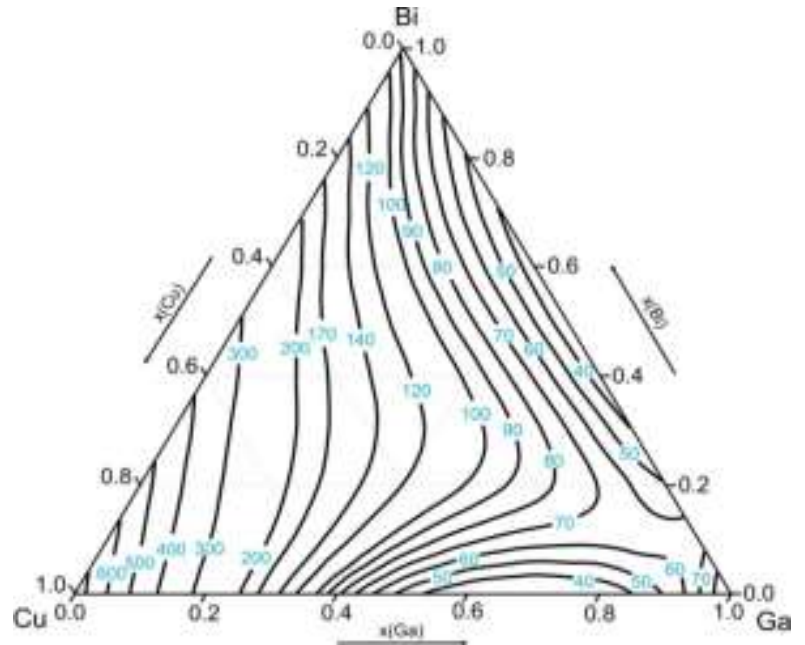

Fig. 6. Iso-lines of Brinell hardness of the ternary Bi-Cu-Ga system at $100^{\circ} \mathrm{C}$

The same ternary alloy samples as well as three binary alloys were used for electrical conductivity measurements. Graphical presentation of the relation between electrical conductivity and mole fraction of components for all investigated samples is shown on Fig. 7. As in case of Brinell hardness, when electrical conductivity of pure elements is considered $\mathrm{Bi}(0.77 \mathrm{MS} / \mathrm{m}), \mathrm{Cu}(59 \mathrm{MS} / \mathrm{m})$ and $\mathrm{Ga}(7.1 \mathrm{MS} / \mathrm{m})$ [34], it can be expected that the electrical conductivity of alloys will increase with an increase of copper content.

From Fig. 7 it can be seen that the electrical conductivity of alloys from $\mathrm{Bi}-\mathrm{CuGa}$ vertical section is decreasing with addition of $\mathrm{Bi}$, on the other hand quite opposite is true for BiGa alloys. As expected, the alloys from the $\mathrm{Cu}$-BiGa vertical section exhibit increase of electrical conductivity with an increase of $\mathrm{Cu}$ content and the $\mathrm{Cu}$ rich $\approx \mathrm{Cu} 90 \mathrm{Bi5Ga5}$ alloy (sample 20) has the highest value of electrical conductivity (31.18 MS/m).
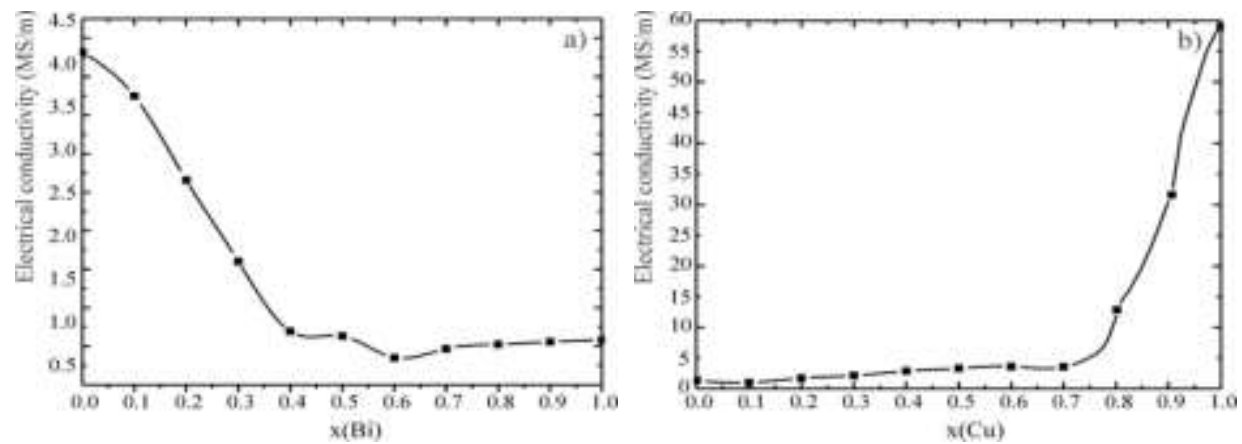


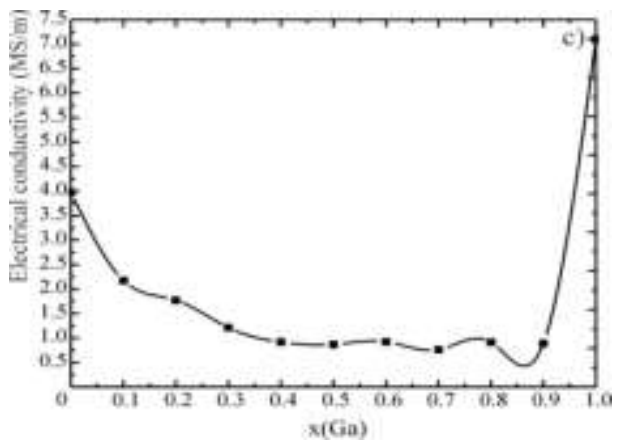

Fig. 7. Graphical presentation of the measured values of electrical conductivity of the investigated alloy samples: a) $\mathrm{Bi}-\mathrm{CuGa}$, b) $\mathrm{Cu}$-BiGa and c) $\mathrm{Ga}-\mathrm{BiCu}$

Calculation of electrical conductivity for the alloys from the Bi-Cu-Ga ternary system was carried out in the same manner as the aforementioned Brinell hardness calculation. Model summary statistics is suggested Quadratic Mixture Model. The final equation of the predictive model in terms of actual components is:

$$
\sigma(M S / m)=-0.3077 \cdot x(B i)+4.09219 \cdot x(C u)+0.94371 \cdot x(\mathrm{Ga})-3.34898 \cdot x(B i) \cdot x(C u)-
$$

\section{$2.38152 \cdot x(\mathrm{Bi}) \cdot x(\mathrm{Ga})-5.54438 \cdot x(\mathrm{Cu}) \cdot x(\mathrm{Ga})$}

Iso-lines contour plot of electric conductivity of the $\mathrm{Bi}-\mathrm{Cu}-\mathrm{Ga}$ alloys defined by equation 2 is shown on Fig. 8.

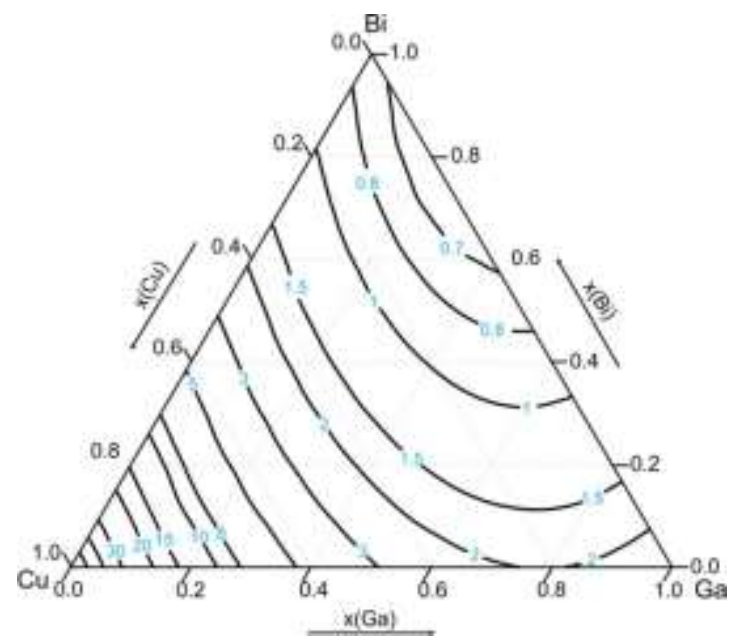

Fig. 8. Iso-lines of electrical conductivity of the ternary Bi-Cu-Ga system at $100{ }^{\circ} \mathrm{C}$

Based on the obtained experimental results and the appropriate mathematical model calculation of electrical conductivity for all alloys from the ternary Bi-Cu-Ga system at $100{ }^{\circ} \mathrm{C}$ was possible. The presented plot on Fig. 8 as such may give information on electrical conductivity for all possible ternary $\mathrm{Bi}-\mathrm{Cu}-\mathrm{Ga}$ alloys. 


\section{Conclusion}

Isothermal section of the ternary $\mathrm{Bi}-\mathrm{Cu}-\mathrm{Ga}$ system at $100{ }^{\circ} \mathrm{C}$ was experimentally and theoretically investigated. The presented theoretical prediction of the isothermal section at $100{ }^{\circ} \mathrm{C}$ was obtained using thermodynamic calculations and literature data for binary subsystems. Seven of fifteen identified regions from the isothermal section at $100{ }^{\circ} \mathrm{C}$ were experimentally tested and in total thirty alloys with compositions along three vertical sections ( $\mathrm{Bi}-\mathrm{CuGa}, \mathrm{Cu}-\mathrm{BiGa}$ and $\mathrm{Ga}-\mathrm{BiCu}$ ) were prepared and studied. The obtained results of microstructure analysis using optical microscopy and SEM support the theoretical predictions rather well. The results of EDS analysis of the alloy composition and composition of present phases confirm existence of the predicted phases in seven tested regions. In the identified (Bi) solid solution $\mathrm{Ga}$ and $\mathrm{Cu}$ solubility was $\approx 1$ at. $\%$ which is negligible. Detected intermetallic compound from binary $\mathrm{Cu}-\mathrm{Ga}$ system $\left(\mathrm{CuGa}_{2}, \gamma_{1}, \gamma_{3}, \zeta^{\prime}\right)$ shows small Ga solubility of maximum 0.54 at. \%. Further phase composition analysis of eighteen alloy samples by XRD has also confirmed predicted phase regions. Apart from confirmation of the phase regions, lattice parameters for the three identified phases were calculated and the results show close agreement with literature data (the difference is on third decimal place). With additional micro-Vickers hardness tests hardness of seven phases was measured.

All thirty alloy samples were characterized in terms of Brinell hardness and electrical conductivity. As expected, it was found that the alloy with the highest $\mathrm{Cu}$ content has the highest hardness and electrical conductivity. Based on obtained experimental results and mathematical calculation iso-lines for Brinell hardness and electrical conductivity were calculated which can provide information on hardness and conductivity for all possible ternary $\mathrm{Bi}-\mathrm{Cu}-\mathrm{Ga}$ alloys.

\section{Acknowledgements}

This work was supported by the Ministry of Education, Science and Technological Development of the Republic of Serbia, under Projects No. ON172037 and TR37020. Calculations were performed by Pandat 8.1 software.

\section{References}

[1] G.P. Vassilev, K.I. Lilova, J.C. Gachon: J. Min. Metall. Sec. B 43 (2) (2007) 141 150.

[2] S. Semboshi, T. Takasugi: J. Alloys Comp. 580 (2013) 397-400.

[3] M. Azimi, G. H. Akbari: J. Alloys Comp. 555 (2013) 112-116.

[4] A. Kamegawa, T. Kuriiwa, M. Okada: J. Alloys Comp. 566 (2013) 1-4.

[5] C. P. Samal, J. S. Parihar, D. Chaira: J. Alloys Comp. 569 (2013) 95-101.

[6] D. Roy, M.A. Atwater, K. Youssef, J.C. Ledford, R.O. Scattergood, C.C. Koch: J. Alloys Comp. 558 (2013) 44-49.

[7] D. Minić, M. Premović, V. Ćosović, D. Manasijević, Lj. Nedeljković, D. Živković: J. Alloys Comp. 617 (2014) 379-388.

[8] S.N. Saud, E. Hamzah, T. Abubakar, H.R. Bakhsheshi-Rad, S. Farahany, A. Abdolahi, M.M. Taheri: J. Alloys Comp. 612(5) (2014) 471-478.

[9] F. Xing, Y. Lu, C. Luo, Y. Ruan, X. Qiu: Mater. Lett. 181 (2016) 42-46.

[10] T. Spassov, S. Gyurov, G. Stefanov, A. Rangelov, L. Drenchev, K. Russew, J. NonCryst. Solids, (2016) 103-107. 
[11] L. Zhou, W.L. Zhou, J.C. Feng, W.X. He, Y.X. Huang, S.S. Dong: Int. J. Adv. Manuf. Technol. 84(5-8) (2016) 1335-1343.

[12] E. Afshari, M. Ghambari, Mater. des. 103(5) (2016) 201-208.

[13] C. Girard, Thesis, University of Provence, Marseille, 1985.

[14] O. Teppo, J. Niemela, P. Taskinen: Thermochim. Acta 173 (1990) 137-150.

[15] J.B. Li, L.N. Ji, J.K. Liang, Y. Zhang, J. Luo, C.R. Li, G.H. Rao: CALPHAD, 32 (2008) 447-453.

[16] N. Puschin, S. Stepanovich, V. Stajić: Z. Anorg. Chem. 209 (1932) 329-334.

[17] W. Kroll: Metallwirtschaft 11 (1932) 435-437.

[18] B. Predel: Z. Phys. Chem. (Frankfurt) 24 (1960) 206-216.

[19] P. Taskinen, J. Niemlä: Scand. J. Metall. 10 (1981) 195-200.

[20] M. Gomez, L. Martin-Garin, H. Ebert, P. Bedon, P. Desré: Z. Metallkde. 67 (1976) 131-134.

[21] J. Niemelä, G. Effenberg, K. Jack, P.J. Spencer: CALPHAD 10 (1986) 77-86.

[22] J.E. Kittl, T.B. Massalski: J. Inst. Met. 65 (1964) 182-188.

[23] W. Lang: Z. Metallkde. 49 (1958) 424-435.

[24] F. Weibke: Z. Anorg. Chem. 220 (1934) 293-311.

[25] A. Dinsdale: CALPHAD 15 (1991) 317-425.

[26] W. Cao, S.-L. Chen, F. Zhang, K. Wu, Y. Yang, Y.A. Chang, R. Schmid-Fetzer, W.A. Oates: CALPHAD 33 (2) (2009) 328-342.

[27] W.P. Davey: Philos. Mag. Serie 647 (1924) 657-671.

[28] R. Stokhuyzen, J.K. Brandon, P.C. Chieh, W.B. Pearson: Acta Crystallogr., Sect. B 30 (1974) 2910-2911.

[29] M. El Boragy, K. Schubert: Z. Metallkde. 63 (1972) 52-53.

[30] http://www.webelements.com/periodicity/hardness_brinell/, Accessed 27 June 2016.

[31] J.A. Cornell: Experiments with Mixtures, 3rd Ed., John Wiley\&Sons, Inc, New York (2002)

[32] Ž. Lazić, Design of Experiments in Chemical Engineering, Wilez-VCH Verlag GmbH\&Co.KGaA, Weiheim (2004)

[33] M. Kolarević, M. Vukićević, B. Radičević, M. Bjelić, V. Grković, In: Proceedings of The Seventh Triennial International Conference Heavy Machinery, (2011), p. 16.

[34] http://periodictable.com/Properties/A/ElectricalConductivity.an.html, Accessed 27 June 2016. 